\title{
KLF2 inhibits cell growth via regulating HIF-1 $\alpha /$ Notch-1 signal pathway in human colorectal cancer HCT116 cells
}

\author{
HAI-GANG WANG, BIN CAO, LI-XIAN ZHANG, NAN SONG, HUI LI, \\ WEN-ZENG ZHAO, YAN-SHU LI, SHUN-MAO MA and DONG-JIAN YIN \\ North China Petroleum Bureau General Hospital, Renqiu, Hebei 062552, P.R. China
}

Received December 7, 2016; Accepted May 15, 2017

DOI: $10.3892 /$ or.2017.5708

\begin{abstract}
The transcription factor Krüppel-like factor 2 (KLF2) has been shown to function as a tumor suppressor and regulate biological processes of cancer cells, such as cell growth, cell apoptosis and angiogenesis. However, the function and mechanism of KLF2 in colorectal cancer (CRC) is still unknown. In the present study, we show that the expression of KLF2 is diminished in a cohort of CRC cell lines. Also, KLF2 overexpression remarkably inhibits HCT116 and SW480 cell survival and proliferation. Moreover, cell death detection ELISA plus assay showed that KLF2 overexpression increased HCT116 cell proliferation. Caspase-3/7 activity also increased in HCT116 cells transfected with PcDNA3.1-KLF2. Further studies showed that KLF2 significantly suppresses the expression of Notch-1 and is dependent on the decline of the HIF-1 $\alpha$ level. Most importantly, silencing Notch-1 expression or HIF-1 $\alpha$ level both impair the action of KLF2 overexpression in CRC cells. Collectively, we demonstrated that KLF2 mediates CRC cell biological processes including cell growth and apoptosis via regulating the HIF- $1 \alpha /$ Notch-1 signal pathway. These results indicated that KLF2 plays an important role in CRC and provided novel insight on the function of KLF2 in tumor progression.
\end{abstract}

\section{Introduction}

Colorectal cancer (CRC) is one of the most common cancers with a high incidence, and one of the leading causes of cancerrelated deaths both in men and women worldwide (1). A large-scale report showed that metastatic CRC is refractory to systemic therapy (2). Although there are some therapies for $\mathrm{CRC}$, such as anticancer drug treatment and antiangiogenic therapies, the overall survival of CRC patients is always very

Correspondence to: Dr Bin Cao, North China Petroleum Bureau General Hospital, Renqiu, Hebei 062552, P.R. China

E-mail: caobin63@163.com

Abbreviations: KLF2, Krüppel-like factor 2; CRC, colorectal cancer; HIF-1 $\alpha$, hypoxia-inducible factor $1 \alpha$

Key words: colorectal cancer, Krüppel-like factor 2, HIF-1 $\alpha$, Notch-1 poor (3). Identifying the function of cancer-related genes in the biology of CRC is a critical step in finding the effective therapeutic approaches for patients with CRC (4). Recent attention has focused on the molecular function and mechanism of $\mathrm{CRC}$ and reports have indicated that several members of the Krüppel-like family play a role in multiple types of cancer, including glioma (5), gastric (6), lung cancer (7) and CRC $(8,9)$.

The KLF (Krüppel-like factors) family which was named due to their homology with Krüppel, is an evolutionarily conserved sequence-specific DNA-binding transcriptional regulator $(10,11)$. KLF family members recognize similar consensus sites because the members contain three conserved zinc fingers (12). KLFs play various and important functions in a number of cellular processes, such as cell differentiation, pluripotency, inflammation, growth, proliferation, apoptosis and migration (13-16). Also, ample evidence suggests that KLF members are involved in the pathobiology of many human diseases, such as metabolic disorders, cardiovascular disease and cancer (17).

KLF2 is one of the KLF family members and has a high expression in fetal and adult lungs, as well as expression in several other organs, including skeletal muscle, heart, spleen and kidney $(18,19)$. It has been well documented that KLF2 plays an important role in numerous cellular physiological processes, including adipogenesis (20), cell differentiation and cell apoptosis (18). Also, KLF2 has been associated with many types of cancers, such as non-small cell lung (21), gastric (22), oral (23), hepatocellular carcinoma (23) and breast cancer (24). $\mathrm{Wu}$ and Lingrel (18) revealed that KLF2 also has expression in CRC cells; however, its specific function is still unknown.

A recent study found that KLF2 could inhibit hypoxiainducible factor $1 \alpha$ (HIF-1 $\alpha)$ expression and also impair its function (25). HIF-1 $\alpha$ is a central regulator of hypoxic response in many cell types, including cancer cells (26). There is convincing evidence that hypoxia plays an important role in tumor progression, angiogenesis, distant metastasis and cancer therapy $(27,28)$. HIF-1 $\alpha$ could mediate multiple oncogenes for cancer progression, including CRC, and inhibition of HIF-1 $\alpha$ has been shown to inhibit the proliferation of human CRC cells (29) and reverses multidrug resistance in CRC cells (30). Also, Wang et al (31) showed that HIF-1 $\alpha$ can bind to the Notch target gene to modulate its signaling in cancer stem cells. The Notch-1 signal also promotes tumorigenesis in CRC and protects cells from apoptosis (32). Thus, we propose that 
the HIF-1 $\alpha /$ Notch-1 signal pathway is implicated in the function of KLF2 in CRC cells. We overexpressed KLF2 in CRC cells to examine the effects of KLF2 on CRC cells growth, and the function of HIF-1 $\alpha /$ Notch-1 signal pathway. The present study demonstrates that overexpression of KLF2 inhibits colorectal cancer growth via regulating the HIF-1 $\alpha /$ Notch-1 signal pathway.

\section{Materials and methods}

Cell culture and transfection. Human SW480 HT29, SW620 and HCT116 CRC cell lines and the normal colon epithelium cell line FHC were obtained from the American Type Culture Collection (ATCC; Manassas, VA, USA). CRC cell lines were cultured in Dulbecco's modified Eagle's medium (DMEM), supplemented with $10 \%$ fetal bovine serum (FBS) and $1 \%$ penicillin-streptomycin. FHC cells were grown in DMEM/ F12 complete medium. All cells were maintained in a humidified atmosphere of $5 \% \mathrm{CO}_{2}$ at $37^{\circ} \mathrm{C}$. SW480 and HCT116 cells were transfected by PcDNA3.1-KLF2, PcDNA3.1/ HIF-1 $\alpha$ or PcDNA3.1-Notch-1 recombinant plasmid by using Lipofectamine 2000 (Invitrogen, Carlsbad, CA, USA) according to the manufacturer's instructions.

Cell survival assay. Human SW480 and HCT116 CRC cells were seeded into 96-well plates at a density of $1 \times 10^{4}$ cells/well. Cells were transfected with PcDNA3.1-KLF2, PcDNA3.1/ HIF-1 $\alpha$ or PcDNA3.1-Notch-1 plasmid. After 24, 48, 72 and 96 h, CellTiter-Blue Cell Viability assay (Promega, Madison, WI, USA) was used to detect the viability of SW480 and HCT116 cells at each time-point according to the manufacturer's instructions.

MTS assay. SW480 and HCT116 CRC cells were seeded into 96-well plates with the appropriate culture medium and transfected with PcDNA3.1-KLF2, PcDNA3.1/ HIF-1 $\alpha$ or PcDNA3.1-Notch-1 plasmid for $48 \mathrm{~h}$. MTS [3,4-(5-dimethylthiazol-2-yl)-5-(3-carboxymethoxy phenyl)2-(4-sulfophenyl)-2H-tetrazolium salt] assays was used to determine cell proliferation according to the manufacturer's protocol (Promega). Cell proliferation was determined as absorbance, which was measured by a microplate reader at OD490.

Cell apoptosis assay. SW480 cells were seeded in 96-well plates and treated as described above. Apoptosis was measured after $48 \mathrm{~h}$ by the Cell Death Detection ELISA plus kit (Roche Diagnostics, Manheim, Germany) according to the manufacturer's protocol. Histone-associated DNA fragments (nucleosomes) were determined according to the method previously described (33). The concentration of nucleosome for each group was normalized for total protein.

Caspase-3/7 activity. SW480 cells were cultured and transfected as described above. Caspase-3/7 activity in cells was measured by using a Caspase-Glo 3/7 assay kit (Promega) following the manufacturer's protocol.

RNA extraction and quantitative real-time PCR. KLF2, HIF- $1 \alpha$ and Notch-1 mRNA expression was determined by quantitative real-time PCR (RT-PCR). Total protein was isolated from SW480 cells by using the RNeasy Plus Mini kit (Qiagen, Germantown, MD, USA). CDNA was synthesized by reverse transcription using reverse transcription reagents (BioRad Laboratories, Hercules, CA, USA). The gene-specific primers used in the present study are as follows: KLF2 (34), 5'-AGACCTACACCAAGAGTTCGCATC-3' (F) and 5'-ATC GCACAGATGGCACTGGAATG-3' (R); HIF-1 $\alpha$ (28), 5'-GT GTTATCTGTCGCTTTGAGTC-3' (F) and 5'-GTCTGGCTG CTGTAATAATGTT-3' (R); Notch-1 (28), 5'-AAGCTGCATC CAGAGGCAAAC-3' (F) and 5'-TGGCATACACACTCCGA GAACAC-3' (R); $\beta$-actin (28), 5'-CACCCACTCCTCCACCT TTG-3' (F) and 5'-CCACCACCCTGTTGCTGTAG-3'.

Western blotting. Western blotting was performed according to the method previously described (28). Total cellular protein was extracted from SW480 cells by using a RIPA buffer (150 mM NaCl, 1\% NP40, $50 \mathrm{mM}$ Tris, $0.5 \%$ sodium deoxycholate and $0.1 \%$ SDS). Protein extractions were separated on $10 \%$ SDS-PAGE and then the proteins were transferred to nitrocellulose (NC) membranes (Sigma-Aldrich, St. Louis, MO, USA). Rabbit anti-human KLF2, HIF-1 $\alpha$ and Notch-1 antibody (Abcam, Cambridge, MA, USA) was used as a primary antibody and HRP goat anti-rabbit IgG antibody (Abcam) was used as a secondary antibody. $\beta$-actin was used as the internal control.

Statistical analysis. All data in the present study are presented as means \pm SD from at least three experiments in triplicate. Statistical analyses were performed using SPSS 19.0 statistical software. Statistical significance for comparisons between groups was carried out by using Student's t-test as well as ANOVA. Test results of $\mathrm{P}<0.05$ were considered statistically significant.

\section{Results}

KLF2 expression is markedly decreased in CRC cell lines. KLF2 has been shown to decrease in various types of cancer and to act as a tumor suppressor. This study aimed to detect the function and mechanism of KLF2 in CRC cell lines. Firstly, we used RT-PCR and western blot analysis to measure the level of KLF2 in controlled normal human colon epithelial cell line FHC, and CRC cell lines SW480, HT29, SW620 and HCT116. As shown in Fig. 1, the mRNA and protein expression was significantly reduced in CRC cell lines compared with the control FHC cell $(\mathrm{P}<0.05)$. Between the CRC cell lines, HCT116 cell lines have obvious effects in the decrease of KLF2, and the SW480 cell line has the highest level.

KLF2 overexpression inhibits CRC cells survival and proliferation. To further examine the effects of KLF2 on CRC cell biological action, KLF2 overexpression SW480 and HCT116 cells were created by transfection with PcDNA3.1 KLF2 recombinant plasmid. After transfection for $48 \mathrm{~h}, \mathrm{KLF} 2$ mRNA and protein expression increased markedly (Fig. 2A and B); KLF2 expression also increased after transfection for 24, 72 and 96 h (data not shown). Next, SW480 and HCT116 cell viability was detected at each time-point. The results indi- 

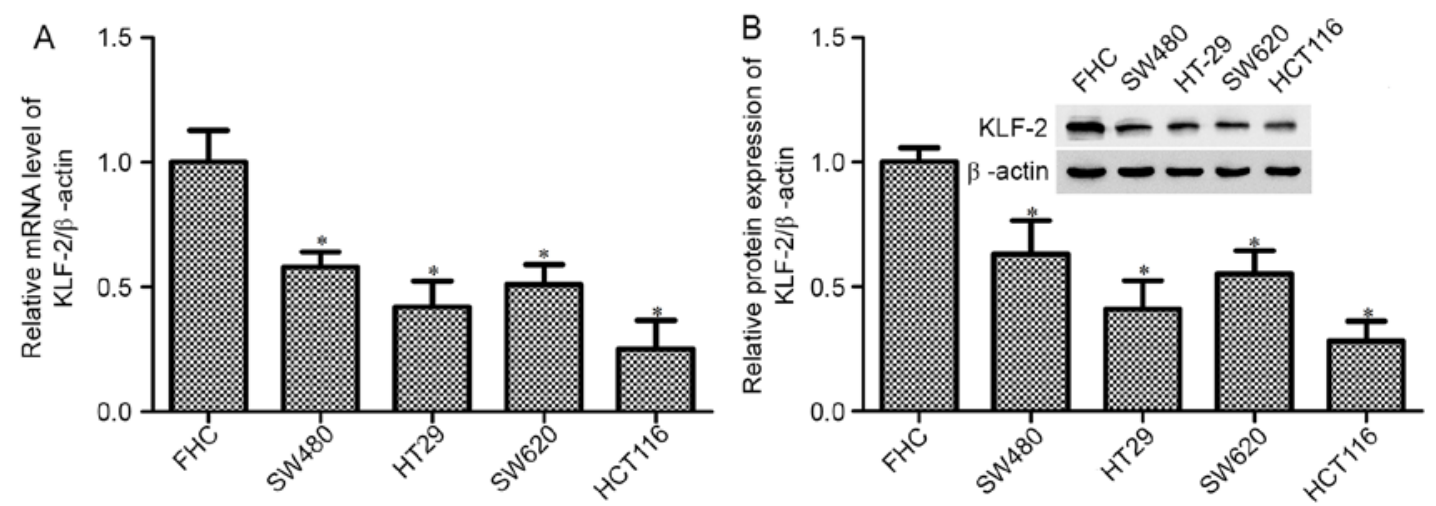

Figure 1. KLF2 expression is reduced in human CRC cell lines (SW480, HT29, SW620 and HCT116) compared with the normal human colon epithelial cells (FHC). (A) KLF2 mRNA expression was detected by RT-PCR assay. (B) Western blot analysis was used to measure KLF2 protein expression. Results are presented as means $\pm \mathrm{SD}$ from at least three experiments in triplicate. ${ }^{*} \mathrm{P}<0.05$ vs. FHC group.

A
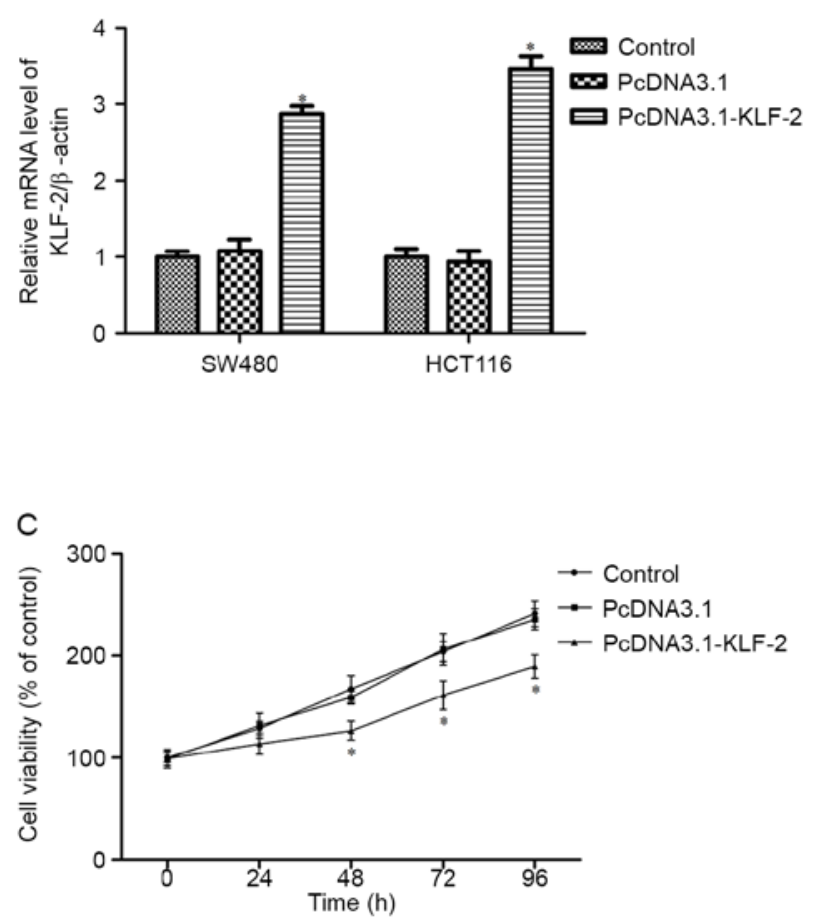

B
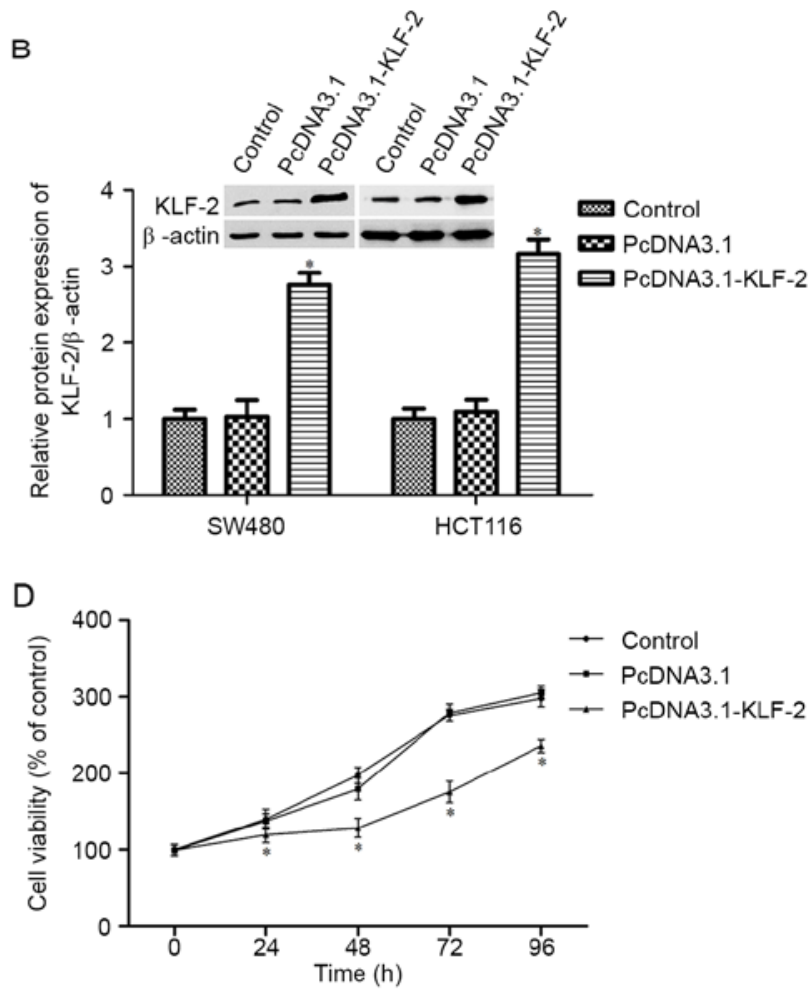

$\mathrm{E}$

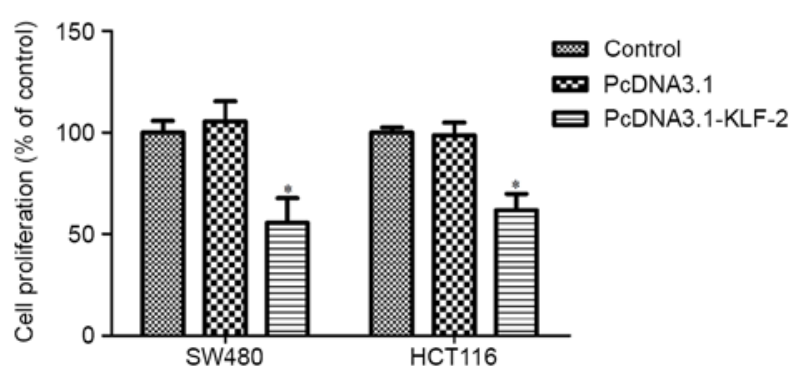

Figure 2. KLF2 overexpression inhibits SW480 and HCT116 cell viability and proliferation. (A) KLF2 mRNA and (B) protein expression was measured by RT-PCR and western blot analysis, respectively. (C) SW480 and (D) HCT116 cell viability was measured by CellTiter-Blue Cell Viability assay. (E) MTS assay was used to determine SW480 and HCT116 cell proliferation. Cells were transfected with PcDNA3.1-KLF2 for 24, 48, 72 and 96 h; results are presented as means \pm SD from at least three experiments in triplicate. ${ }^{*} \mathrm{P}<0.05$ vs. control.

cated that KLF2 overexpression inhibits SW480 and HCT116 cell viability compared with the control and PcDNA3.1 empty plasmid group ( $\mathrm{P}<0.05$; Fig. $2 \mathrm{C}$ and $\mathrm{D})$. Cell proliferation was measured by the MTS method; the results showed that KLF2 

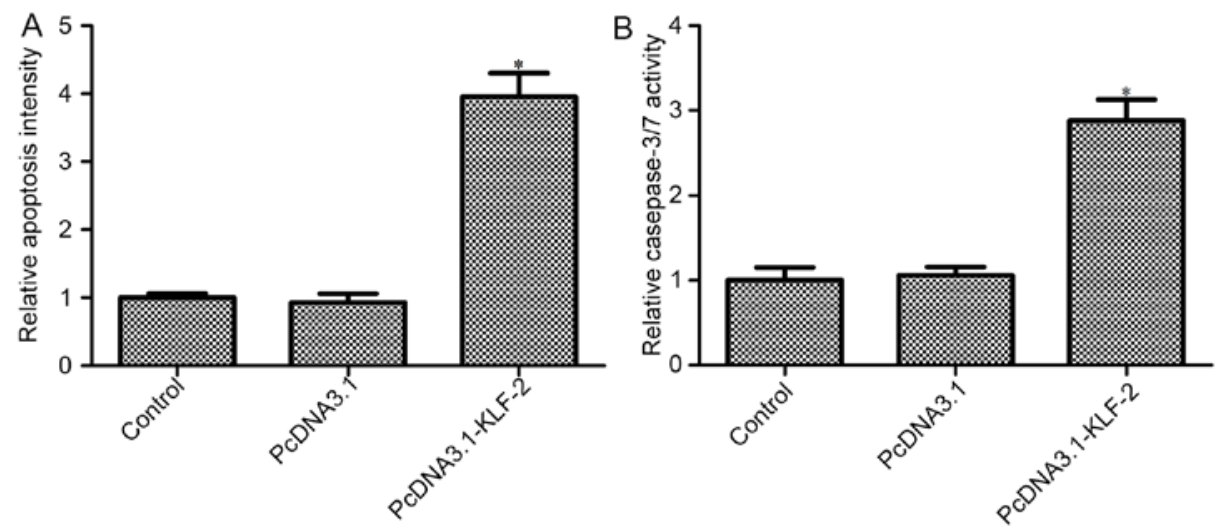

Figure 3. Induction of apoptosis by KLF2 overexpression in HCT116 cells. (A) HCT116 cell apoptosis was quantified by detecting histone-associated-DNAfragmentation using cell death detection ELISA plus assay. (B) Caspase-Glo 3/7 assay kit was used to determine the activity of caspase-3/7 in HCT116 cells. Cells were transfected with PcDNA3.1-KLF-2 for $48 \mathrm{~h}$; results are presented as means \pm SD from at least three experiments in triplicate. ${ }^{*} \mathrm{P}<0.05$ vs control.
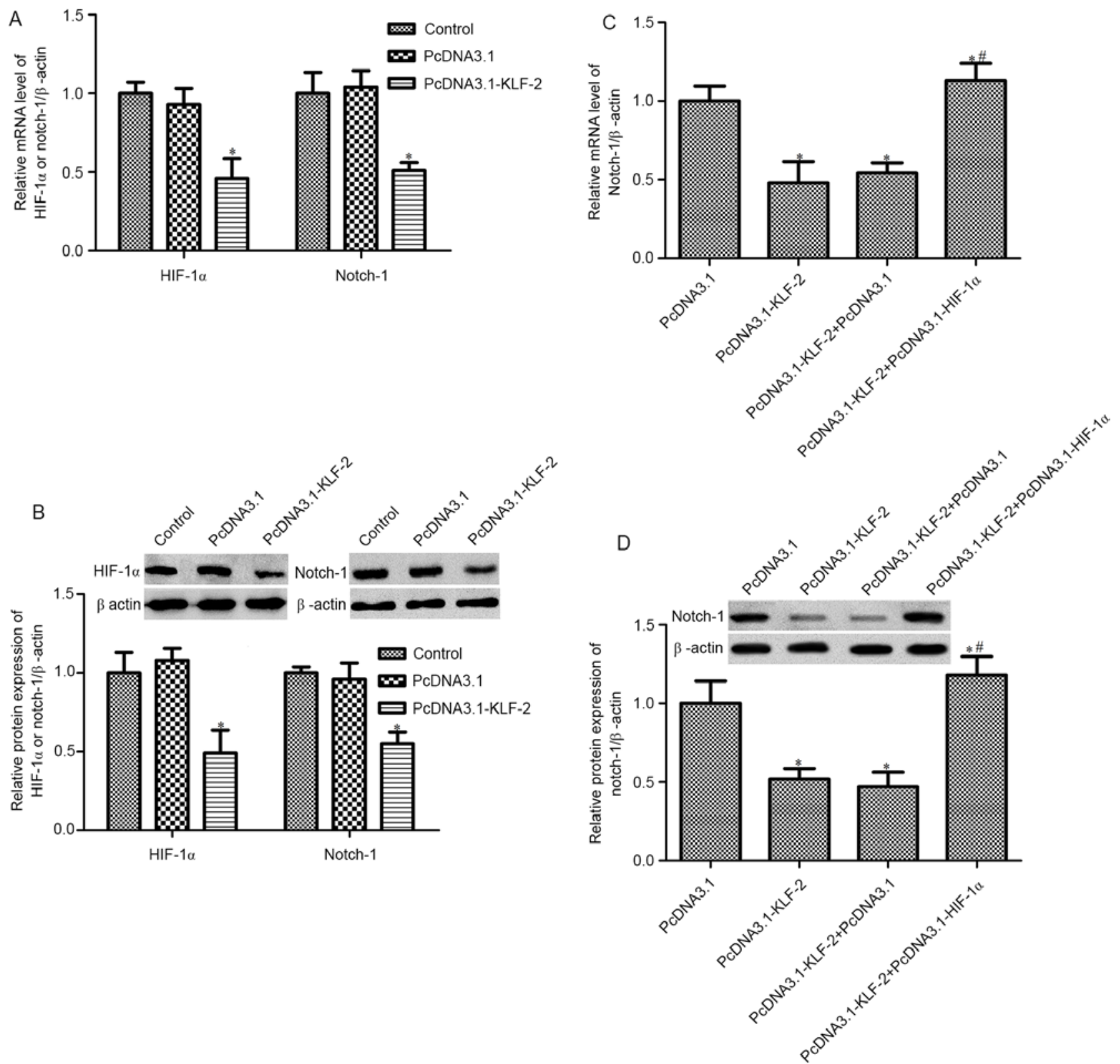

Figure 4. KLF2 overexpression suppresses Notch-1 expression via inhibiting HIF-1 $\alpha$. (A) HIF-1 $\alpha$ and Notch-1 mRNA and (B) protein expression was measured by RT-PCR and western blot analysis, respectively. (C) Notch-1 mRNA and protein (D) expression was measured by RT-PCR and western blot analysis, respectively. Cells were transfected with PcDNA3.1-KLF-2 or co-transfected with PcDNA3.1-KLF-2 and PcDNA3.1-HIF-1 $\alpha$ for $48 \mathrm{~h}$; results are presented as means \pm SD from at least three experiments in triplicate. ${ }^{*} \mathrm{P}<0.05$ vs. control or PcDNA3.1 group, ${ }^{\sharp *} \mathrm{P}<0.05$ vs. PcDNA3.1-KLF-2 group. 


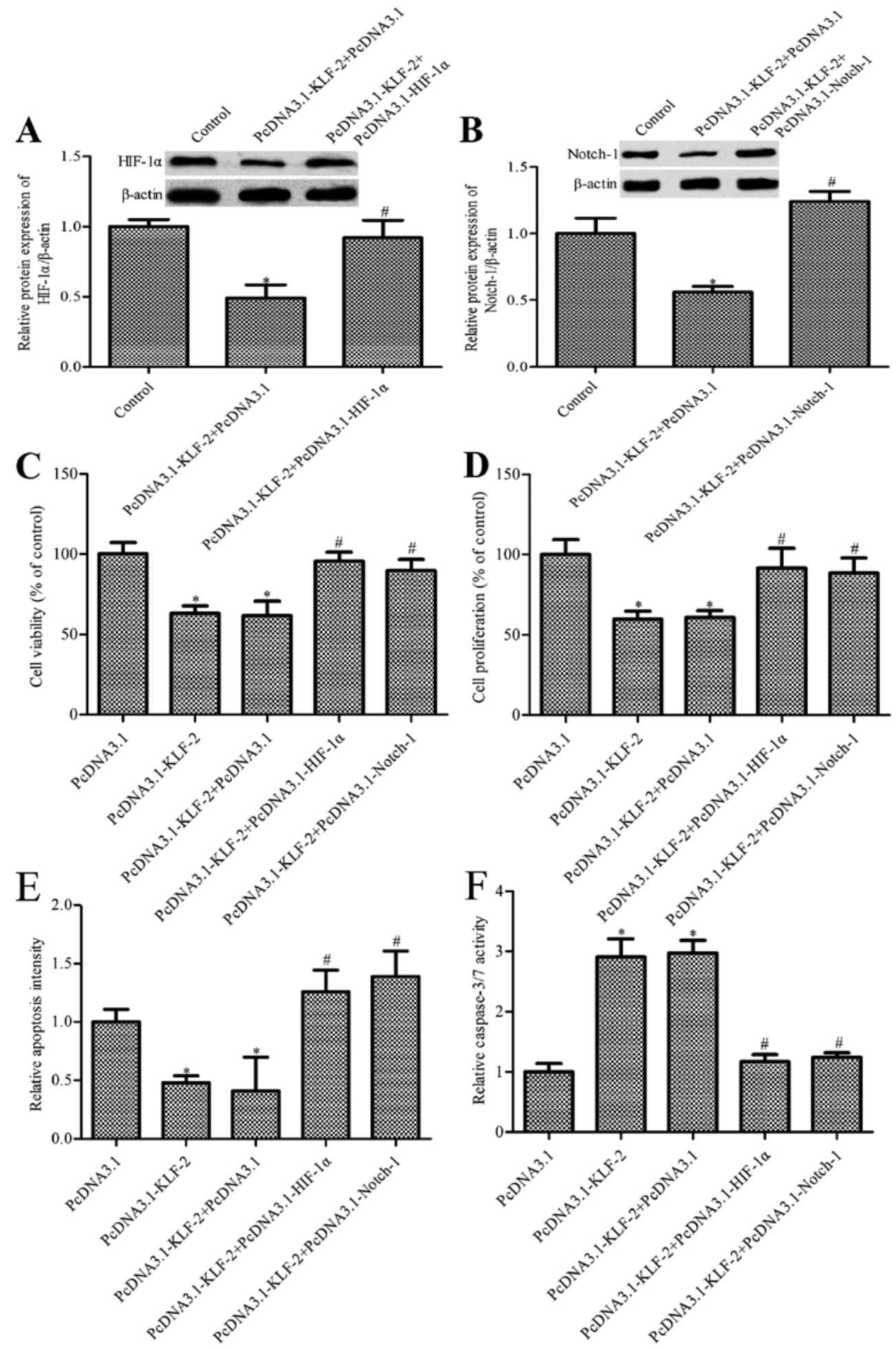

Figure 5. Induction growth inhibition and apoptosis by KLF2 overexpression in HCT116 cells are dependent on HIF-1 $\alpha /$ Notch-1 signal pathway. (A) HIF-1 $\alpha$ protein expression was measured by western blot analysis. (B) Notch-1 protein expression was measured by western blot analysis. (C) HCT116 cell viability was measured by CellTiter-Blue Cell Viability assay. (D) MTS assay was used to determine HCT116 cell proliferation. (E) HCT116 cell apoptosis was quantified by using cell death detection ELISA plus assay. (F) Caspase-Glo 3/7 assay kit was used to determine the activity of caspase-3/7 in HCT116 cells. Cells were co-transfected with PcDNA3.1-KLF-2 and PcDNA3.1-HIF-1 $\alpha$ or PcDNA3.1-KLF-2 and PcDNA3.1-Notch-1 for 48 h; results are presented as means \pm SD from at least three experiments in triplicate. ${ }^{*} \mathrm{P}<0.05$ vs. control or PcDNA3.1 group, ${ }^{\# *} \mathrm{P}<0.05$ vs. PcDNA3.1-KLF-2 group.

overexpression for $48 \mathrm{~h}$ remarkably suppressed SW480 and HCT116 cell proliferation ( $\mathrm{P}<0.05$; Fig. 2E).

KLF2 overexpression promotes CRC cell apoptosis. We further studied the effects of KLF2 overexpression on HCT116 cell apoptosis, and histone-associated DNA fragments (nucleosomes) in HCT116 cells were measured. The level of nucleosomes increased in PcDNA3.1-KLF2 transfected cells compared with the control group $(\mathrm{P}<0.05$; Fig. 3A), whereas the level of nucleosomes in the PcDNA3.1 group had no 
obvious change compared with the control group ( $\mathrm{P}>0.05$; Fig. 3A). The results indicated that KLF2 overexpression promotes HCT116 cell apoptosis. We also demonstrated the results by determining the level of caspase-3/7. The results of the Caspase-Glo 3/7 assay showed that KLF2 overexpression increased caspase-3/7 activity compared with the control and PcDNA3.1 empty plasmid group $(\mathrm{P}<0.05$; Fig. $3 \mathrm{~B})$.

KLF2 inhibit Notch-1 expression via inhibiting HIF-1 . In order to verify the mechanism of KLF2 in HCT116 cell biological action, further studies focused on the effects of KLF2 on HIF-1 $\alpha /$ Notch-1 expression. RT-PCR and western blot analysis was used to detect the mRNA and protein level of HIF-1 $\alpha$ and Notch-1, respectively. A reduction in HIF-1 $\alpha$ and Notch-1 mRNA and protein expression was observed by KLF2 overexpression (Fig. 4A and B). Furthermore, we constructed PcDNA3.1-KLF2 and PcDNA3.1-HIF-1 $\alpha$ co-transfected HCT116 cells; the expression of Notch-1 was measured. As shown in Fig. 4C and D, PcDNA3.1-KLF2 and PcDNA3.1HIF-1 $\alpha$ co-transfected impaired the decrease of Notch-1 expression induced by PcDNA3.1-KLF2 only, both in mRNA and protein expression. These results indicated that KLF2 inhibits Notch-1 expression via inhibiting HIF-1 $\alpha$ in HCT116 cells.

KLF2 overexpression regulates HCT116 cell growth via HIF-1 $\alpha /$ Notch-1 signal pathway. To further depict the function and mechanism of KLF2 overexpression in HCT116 cells, we constructed PcDNA3.1-KLF2 and PcDNA3.1HIF-1 $\alpha$ co-transfected cells, and PcDNA3.1-KLF2 and PcDNA3.1-Notch-1 co-transfected cells. The results in Fig. 5A and B have showed that compared with the PcDNA3.1-KLF2 + PcDNA3.1 group, the level of HIF-1 $\alpha$ or Notch1 was markedly increased in the PcDNA3.1-KLF2 + PcDNA3.1-HIF-1 $\alpha$ group or PcDNA3.1-KLF2 + PcDNA3.1Notch1 group, respectively. Cell biology including viability, proliferation and apoptosis were measured. As shown in Fig. 5C and D, PcDNA3.1-KLF2 and PcDNA3.1-HIF-1 $\alpha$ co-transfection or PcDNA3.1-KLF2 and PcDNA3.1-Notch-1 co-transfection strengthened HCT116 cell survival and proliferation compared with the PcDNA3.1-KLF2 group. We also found that HIF-1 $\alpha$ overexpression or Notch-1 overexpression impaired the decrease of PcDNA3.1-KLF2 induced CRC cell apoptosis (Fig. 5E). Finally, caspase-3/7 level was determined, similarly to the above results; caspase3/7 level in PcDNA3.1-KLF2 and PcDNA3.1-HIF-1 $\alpha$ co-transfected or PcDNA3.1-KLF2 and PcDNA3.1-Notch-1 co-transfected group markedly decreased compared with the KLF2 overexpression group (Fig. 5F). The above results suggested that KLF2 overexpression regulates HCT116 cell growth, and apoptosis is dependent on the silencing of the HIF-1 $\alpha /$ Notch-1 signal pathway.

\section{Discussion}

The main findings in the present study are as follows. First, KLF2 decreased in various CRC cell lines (SW480, HT29, SW620 and HCT116) compared with the control human colon epithelial cell line FHC. Recently, numerous pieces of evidence show that members of the Krüppel-like factor family play essential roles cancers, including CRC $(7,9)$. It is now well established that the KLF proteins with Cys2/His2 zinc-finger domains play a pivotal role in cell proliferation, differentiation and could be characterized as suppressors or activators in various cell types, including cancer cells (15). KLF2 is a tumor-suppressor associated with cancer pathogenesis. The KLF member KLF2 has shown a generally low expression in many malignancies, such as prostate (35) and ovarian (36) cancer. Consistent with these reports, the present study showed that KLF2 is diminished in CRC cell lines, thus, we supposed that dys-regulated expression of KLF2 may affect the biofunction of CRC cells.

Overexpression of KLF2 in SW480 and HCT116 cells remarkably inhibits SW480 and HCT116 cell survival and proliferation; moreover, overexpression of KLF2 promotes HCT116 cell apoptosis and caspase-3 activity. KLF2 has been shown to function as a tumor suppressor, such as inhibiting cell growth, increasing DNA-damage-associated apoptosis, anti-angiogenesis properties and the induction of cell quiescence (37). Nie and colleagues (21) showed that silencing KLF2 expression promotes non-small cell lung cancer cell proliferation and inhibits apoptosis. Wu and Lingrel (18) showed that KLF2 could inhibit Jurkat T leukemia cell growth via mediated $\mathrm{p} 21^{\mathrm{WAF} 1 / \mathrm{CIP} 1}$ expression. Consistent with these reports, our results provide preliminary data regarding the inhibition role of KLF2 in CRC cell growth and the promotion role in CRC apoptosis.

KLF2 could inhibit the Notch-1 level via inhibiting HIF-1 $\alpha$ expression; furthermore, a HIF-1 $\alpha /$ Notch-1 signal was implicated in KLF2 action in CRC cells. KLF members were associated with a burst of cancer progression by regulating various oncogenes (5). Also, evidence has suggested that KLF2 could mediate the level of HIF-1 $\alpha$ (25). There is convincing evidence that HIF-1 $\alpha$ functions as ancogene in CRC. Zhang et al (38) showed that HIF-1 $\alpha$ is linked to the angiogenesis and epithelial-mesenchymal transition, which is mediated by LRG1 in colorectal cancer. Huynh and colleagues (39) showed that glaucarubinone suppresses CRC progression via downregulating the expression of HIF-1 $\alpha$. Moreover, it is well accepted that Notch-1 is associated with HIF-1 $\alpha$ induced-cancer progression (40). In the present study, we demonstrated that KLF2 inhibits CRC cell growth via mediating the HIF- $1 \alpha /$ Notch-1 signal pathway.

Collectively, the present results provide the first evidence that KLF2 inhibits CRC cell growth via inhibiting the HIF-1 $\alpha$ / Notch-1 signal pathway. KLF2 is characterized as a tumor suppressor in CRC, suggesting it may provide new targets for the biology of CRC.

\section{References}

1. Siegel R, Desantis $C$ and Jemal A: Colorectal cancer statistics, 2014. CA Cancer J Clin 64: 104-117, 2014.

2. Davies JM and Goldberg RM: First-line therapeutic strategies in metastatic colorectal cancer. Oncology (Williston Park) 22: 1470-1479, 2008

3. Lu J, Ye X, Fan F, Xia L, Bhattacharya R, Bellister S, Tozzi F, Sceusi E, Zhou Y, Tachibana I, et al: Endothelial cells promote the colorectal cancer stem cell phenotype through a soluble form of Jagged-1. Cancer Cell 23: 171-185, 2013.

4. Cai C, Ashktorab H, Pang X, Zhao Y, Sha W, Liu Y and Gu X: MicroRNA-211 expression promotes colorectal cancer cell growth in vitro and in vivo by targeting tumor suppressor CHD5. PLoS One 7: e29750, 2012. 
5. Huang S, Wang C, Yi Y, Sun X, Luo M, Zhou Z, Li J, Cai Y, Jiang $X$ and Ke Y: Krüppel-like factor 9 inhibits glioma cell proliferation and tumorigenicity via downregulation of miR-21. Cancer Lett 356: 547-555, 2015.

6. Zhang H, Sun L, Xiao X, Xie R, Liu C, Wang Y, Wei Y, Zhang $\mathrm{H}$ and Liu L: Krüppel-like factor 8 contributes to hypoxia-induced MDR in gastric cancer cells. Cancer Sci 105: 1109-1115, 2014

7. Fadous-Khalifé MC, Aloulou N, Jalbout M, Hadchity J, Aftimos G, Paris F and Hadchity E: Krüppel-like factor 4: A new potential biomarker of lung cancer. Mol Clin Oncol 5: 35-40, 2016.

8. Kim SH, Park YY, Cho SN, Margalit O, Wang D and DuBois RN: Krüppel-like factor 12 promotes colorectal cancer growth through early growth response protein 1 . PLoS One 11: e0159899, 2016.

9. Brown AR, Van TT, Simmen RC and Simmen FA: The potential tumor-suppressive role of Krüppel-like factor 9 in colorectal cancer. Cancer Res 73 (8 Suppl): 1969-1969, 2013.

10. Bieker JJ: Krüppel-like factors: Three fingers in many pies. J Biol Chem 276: 34355-34358, 2001.

11. Preiss A, Rosenberg UB, Kienlin A, Seifert E and Jäckle H: Molecular genetics of Krüppel, a gene required for segmentation of the Drosophila embryo. Nature 313: 27-32, 1985.

12. Eaton SA, Funnell AP, Sue N, Nicholas H, Pearson RC and Crossley M: A network of Krüppel-like Factors (Klfs). Klf8 is repressed by Klf3 and activated by Klf1 in vivo. J Biol Chem 283: 26937-26947, 2008.

13. Tetreault MP, Yang Y and Katz JP: Krüppel-like factors in cancer. Nat Rev Cancer 13: 701-713, 2013.

14. Dang DT, Pevsner J and Yang VW: The biology of the mammalian Krüppel-like family of transcription factors. Int J Biochem Cell Biol 32: 1103-1121, 2000.

15. Black AR, Black JD and Azizkhan-Clifford J: Sp1 and Krüppellike factor family of transcription factors in cell growth regulation and cancer. J Cell Physiol 188: 143-160, 2001.

16. Kaczynski J, Cook T and Urrutia R: Sp1- and Krüppel-like transcription factors. Genome Biol 4: 206, 2003.

17. McConnell BB and Yang VW: Mammalian Krüppel-like factors in health and diseases. Physiol Rev 90: 1337-1381, 2010.

18. Wu J and Lingrel JB: KLF2 inhibits Jurkat T leukemia cell growth via upregulation of cyclin-dependent kinase inhibitor p21WAF1/CIP1. Oncogene 23: 8088-8096, 2004.

19. Wang N, Miao H, Li YS, Zhang P, Haga JH, Hu Y, Young A, Yuan S, Nguyen P, Wu CC, et al: Shear stress regulation of Krüppel-like factor 2 expression is flow pattern-specific. Biochem Biophys Res Commun 341: 1244-1251, 2006.

20. Banerjee SS, Feinberg MW, Watanabe M, Gray S, Haspel RL, Denkinger DJ, Kawahara R, Hauner $\mathrm{H}$ and Jain MK: The Krüppel-like factor KLF2 inhibits peroxisome proliferatoractivated receptor-gamma expression and adipogenesis. J Biol Chem 278: 2581-2584, 2003

21. Nie FQ, Sun M, Yang JS, Xie M, Xu TP, Xia R, Liu YW, Liu XH, Zhang EB, Lu KH, et al: Long noncoding RNA ANRIL promotes non-small cell lung cancer cell proliferation and inhibits apoptosis by silencing KLF2 and P21 expression. Mol Cancer Ther 14: 268-277, 2015.

22. Xu TP, Liu XX, Xia R, Yin L, Kong R, Chen WM, Huang MD and Shu YQ: SP1-induced upregulation of the long noncoding RNA TINCR regulates cell proliferation and apoptosis by affecting KLF2 mRNA stability in gastric cancer. Oncogene 34 5648-5661, 2015

23. Uchida D, Onoue T, Begum NM, Kuribayashi N, Tomizuka Y, Tamatani T, Nagai H and Miyamoto Y: Vesnarinone downregulates CXCR4 expression via upregulation of Krüppel-like factor 2 in oral cancer cells. Mol Cancer 8: 62, 2009.
24. Ebert R, Zeck S, Meissner-Weigl J, Klotz B, Rachner TD, Benad P, Klein-Hitpass L, Rudert M, Hof bauer LC and Jakob F: Krüppel-like factors KLF2 and 6 and Ki-67 are direct targets of zoledronic acid in MCF-7 cells. Bone 50: 723-732, 2012.

25. Kawanami D, Mahabeleshwar GH, Lin Z, Atkins GB, Hamik A, Haldar SM, Maemura K, Lamanna JC and Jain MK: Kruppellike factor 2 inhibits hypoxia-inducible factor 1alpha expression and function in the endothelium. J Biol Chem 284: 20522-20530, 2009.

26. Semenza GL: Targeting HIF-1 for cancer therapy. Nat Rev Cancer 3: 721-732, 2003.

27. Shen G, Li X, Jia YF, Piazza GA and Xi Y: Hypoxia-regulated microRNAs in human cancer. Acta Pharmacol Sin 34: 336-341, 2013.

28. Tian Q, Xue Y, Zheng W, Sun R, Ji W, Wang X and An R: Overexpression of hypoxia-inducible factor $1 \alpha$ induces migration and invasion through Notch signaling. Int J Oncol 47: 728-738, 2015.

29. Cárdeno A, Sánchez-Hidalgo M, Rosillo MA and Alarcón de la Lastra C: Oleuropein, a secoiridoid derived from olive tree, inhibits the proliferation of human colorectal cancer cell through downregulation of HIF-1 $\alpha$. Nutr Cancer 65: 147-156, 2013.

30. Chen J, Ding Z, Peng Y, Pan F, Li J, Zou L, Zhang Y and Liang H: HIF-1alpha inhibition reverses multidrug resistance in colon cancer cells via downregulation of MDR1/P-glycoprotein. PLoS One 9: 92014, 2014.

31. Wang Y, Liu Y, Malek SN, Zheng P and Liu Y: Targeting HIF1a eliminates cancer stem cells in hematological malignancies. Cell Stem Cell 8: 399-411, 2011.

32. Meng RD, Shelton CC, Li YM, Qin LX, Notterman D, Paty PB and Schwartz GK: gamma-Secretase inhibitors abrogate oxaliplatin-induced activation of the Notch-1 signaling pathway in colon cancer cells resulting in enhanced chemosensitivity. Cancer Res 69: 573-582, 2009.

33. Thacker SA, Robinson P, Abel A and Tweardy DJ: Modulation of the unfolded protein response during hepatocyte and cardiomyocyte apoptosis in trauma/hemorrhagic shock. Sci Rep 3: 1187, 2013.

34. Macari ER, Schaeffer EK, West RJ and Lowrey CH: Simvastatin and t-butylhydroquinone suppress KLF1 and BCL11A gene expression and additively increase fetal hemoglobin in primary human erythroid cells. Blood 121: 830-839, 2013.

35. Duhagon MA, Hurt EM, Sotelo-Silveira JR, Zhang $X$ and Farrar WL: Genomic profiling of tumor initiating prostatospheres. BMC Genomics 11: 324, 2010.

36. Wang F, Zhu Y, Huang Y, McAvoy S, Johnson WB, Cheung TH, Chung TK, Lo KW, Yim SF, Yu MM, et al: Transcriptional repression of WEE1 by Kruppel-like factor 2 is involved in DNA damage-induced apoptosis. Oncogene 24: 3875-3885, 2005.

37. Taniguchi H, Jacinto FV, Villanueva A, Fernandez AF, Yamamoto H, Carmona FJ, Puertas S, Marquez VE, Shinomura Y, Imai K, et al: Silencing of Kruppel-like factor 2 by the histone methyltransferase EZH2 in human cancer. Oncogene 31: 1988-1994, 2012

38. Zhang J, Zhu L, Fang J, Ge Z and Li X: LRG1 modulates epithelial-mesenchymal transition and angiogenesis in colorectal cancer via HIF-1alpha activation. J Exp Clin Cancer Res 35: 016-0306, 2016.

39. Huynh N, Beutler JA, Shulkes A, Baldwin GS and He H: Glaucarubinone inhibits colorectal cancer growth by suppression of hypoxia-inducible factor $1 \alpha$ and $\beta$-catenin via a $p-21$ activated kinase 1-dependent pathway. Biochim Biophys Acta 1853: 157-165, 2015.

40. Qiang L, Wu T, Zhang HW, Lu N, Hu R, Wang YJ, Zhao L, Chen FH, Wang XT, You QD, et al: HIF-1 $\alpha$ is critical for hypoxiamediated maintenance of glioblastoma stem cells by activating Notch signaling pathway. Cell Death Differ 19: 284-294, 2012. 